\title{
Sexual Harassment: Experiences of Japanese Women Studying in Canada
}

\section{Chad Fryer and Lily Wong}

Many Canadians in large and small cities are now familiar with the sight of Japanese students studying English at local community colleges or language schools. The students arrive in Canada eager to learn a language and to take in as much Canadian culture as they can during their often brief stay. Unfortunately, some aspects of the cultural experiences that these students have reveal a disturbing characteristic of our society.

\section{The Problem}

We have been involved with Japanese students in various capacities for the last 10 years as ESL teachers and members of a host family. As a result, we have had contact with many female Japanese students and understand the educational program that they receive. However, we were startled when we began to hear of incidents of various degrees of sexual harassment from numerous students. The first story originated from a homestay student during a trip she took with a classmate to Victoria, British Columbia. We had suggested that she stay at a Bed and Breakfast (B\&B), because these accommodations provide a more personal experience as opposed to a hotel and are relatively inexpensive. When the two women returned from their trip, they told us a disturbing story. The proprietor, who was an older man, continually hugged them and justified his action by saying it was a Canadian custom. Upon telling the story, the women thought the situation was humorous, but at the time had been so uncomfortable that they made every effort to avoid interacting with this man. However, he still managed to hug them in a full body embrace three times in two days. We expressed surprise at this incident and suggested they should report the establishment. The students were not particularly concerned with following up this complaint as they were returning to Japan in two weeks.

At the time of this first incident, we were in the process of collecting data for a research project about Japanese students studying English in Vancouver and thus decided to ask other students if they also had any "strange" experiences while in Canada. We were unprepared for the number and extent of incidents of harassment to which these women were subjected. The following highlights some of the accounts that were shared with us.

- A young woman was asked while sitting on a bench in Stanley Park if she wanted to visit the Capilano Suspension Bridge. She accepted the 
offer, and during the drive to their destination, the man began touching her.

- A young woman agreed to participate in a language exchange with a man she met at the Vancouver Public Library. After the meeting he tried to kiss her.

- A young woman held the door of an office building open for a man. While walking through he pinched her cheek and said, "You are so cute."

- A young woman was touched on her stomach by a stranger as they passed on a crosswalk on Robson and Burrard Street. She turned around and saw him smiling at her.

- A young woman attended a fireworks display at English Bay with her male English teacher. He held her hand and said, "Friends hold hands in Canada."

None of the situations was reported to teachers or school administrators, but in some instances the students related the events to their homestay families. We believe many students did not initiate action against these individuals because they did not want to spend their time abroad embroiled in legal action or dwelling on an unpleasant episode. For many of the students, their time overseas was often a year or less.

We cannot assume that all Japanese students have negative experiences but can only illustrate the occurrences that have been related to us by the students whom we have encountered. However, because a large percentage of these women share similar stories, we believe many others are also affected.

\section{Solutions}

Many people have told us that these students should have better sense than to trust a stranger, as has occurred in several of the incidents. This is a valid point, but the students believe that the best way to learn English and about Canadian culture is to interact with Canadians. As well, some of these students are so overwhelmed by a new culture that they are open to friendly gestures that Canadian women would probably rebuff.

As a result, there is an onus on people in contact with Japanese and other international students such as fellow ESL teachers, homestay families, and individuals who care about Canada's international reputation as a safe country to provide guidance on what is safe conduct in Canadian cities in the 1990s. We firmly believe this responsibility is the first necessary step in combating the problem, but by no means the only one.

In the search for solutions we targeted several places and people for help: a sexual harassment advisor at the UBC Equity Office, a university anti-oppression educator, the UBC Law Student Assistance Program, a local Women's Resource Center, and finally the head of security at Vancouver 
Public Library. All parties were supportive and emphasized the need for these women immediately to notify authorities at their school or in public facilities where the incidents occur. Such complaints will bring greater awareness of harassment to educators and officials at local institutions. However, as mentioned above many students are not willing to lodge a complaint.

The Women's Resource Center provided a further suggestion by offering an assertiveness workshop for school staff and students for a nominal fee. Some of the skills include practicing assertive language such as saying " $\mathrm{No}^{\text {" }}$ in a clear and firm manner; using assertive body language when walking alone; maintaining one's personal space with others; basic self-defense techniques; and finally integrating these physical and verbal skills through roleplays. Although these workshops are helpful as they provide women with proactive skills as well as ways to respond effectively during incidents of sexual harassment, they are only one element of the solution.

Of course, the real problem is not the Japanese students, but rather the men who feel they can behave in this manner. We believe the targeting of Japanese female students often combines sexual harassment and racism. The racism stems from the racist stereotype of Japanese women being innocent, subservient, and unwilling to complain. These assumptions are problematic at best, but the fact that these students are struggling with a new language and culture significantly heightens their vulnerability.

\section{Conclusion}

People often relate to us that they enjoy being friendly to Japanese international students. In an ideal world, friendliness is a wonderful gesture, yet one merely has to read the newspaper to realize that no city or town is completely safe. As shown in several of the incidents, "Canadian customs" were being used as a pretext by some men as a means of touching and making advances toward Japanese women. These gestures, of course, can also be used to indicate signs of friendship but understanding the circumstances when they are appropriate often requires a cultural familiarity that the students lack. As a result, there exists a serious need to educate these women in a more comprehensive manner on what constitutes culturally appropriate behavior versus sexual harassment.

We certainly do not have a definitive solution to this problem and in fact have only scratched the surface. Yet we have a responsibility to prepare these Japanese women for life in Canada, which might include an assertiveness training workshop, education on sexual harassment, and viable options if and when incidents occur. Perhaps of greater urgency is the need to educate the Canadian men who feel that taking advantage of these women who are studying abroad is acceptable behavior. We hope other educators and host 
families share our concern, and as a result will become involved in social activism against this form of sexual harassment.

\section{The Authors}

Chad Fryer is a graduate research student at Nagoya University in Japan. He has a master's degree in curriculum and instruction from the University of British Columbia. He previously taught ESL in Canada and at Nagoya Gakuin University in Japan.

Lily Wong is an elementary ESL specialist at Nagoya International School. She is currently completing her MA in applied linguistics from Leicester University in England. She has taught ESL in Canada and Japan. 